\title{
ICCM2015: A Comparison of RANS and LES Computational Methods in Analyzing Ventilation Flow Through a Room Fitted with a Two-Sided Windcatcher
}

\author{
A.Niktash $\dagger^{\prime}$ and B.P. Huynh ${ }^{1}$ \\ ${ }^{1}$ School of Electrical, Mechanical and Mechatronic Systems, \\ Faculty of Engineering \& IT, University of Technology, Sydney, Australia \\ †Corresponding author: amirreza.niktash@uts.edu.au
}

\begin{abstract}
A windcatcher is a structure for providing natural ventilation using wind power; it is usually fitted on the roof of a building to exhaust the inside stale air to the outside and supplies the outside fresh air into the building interior space working by pressure difference between outside and inside of the building. In this paper, the behaviour of free wind flow through a three-dimensional room fitted with a centred position two-canal bottom shape windcatcher model is investigated numerically, using a commercial computational fluid dynamics (CFD) software package and LES (Large Eddy Simulation) CFD method. The results have been compared with the obtained results for the same model but using RANS (Reynolds Averaged Navier-Stokes) CFD method. The model with its surrounded space has been considered in both method. It is found that the achieved results for the model from LES method are in good agreement with RANS method's results for the same model.
\end{abstract}

Keywords: CFD, Human comfort, K-E, LES, RANS, Simulation, Ventilation, Windcatcher

\section{Introduction}

Windcatcher is one of the green features for providing natural ventilation using wind power which has been employed over centuries in the hot arid parts of Iran and the other Persian Gulf countries to provide natural ventilation, passive cooling and thermal comfort [Fathy and Walter(1986); Karakastanis et al. (1986); Montazeri et al. (2010)].

The low cost of windcatcher system in comparison with mechanical ventilation system, being noiseless, durability, requiring no fossil energy, supplying clean air and using sustainable energy of wind power have led to use of the windcatcher as a passive and environmental friendly system.

The cross sections of all windcatchers which have circular or square shapes are divided internally into various segments to get one-sided, two-sided, three-sided, four-sided, hexahedral, and octahedral windcatchers to make the windcatcher system safer to periodic wind changes [Liu and Mak (2007)]. Some traditional windcatchers with different number of opening have been shown in Figure 1.
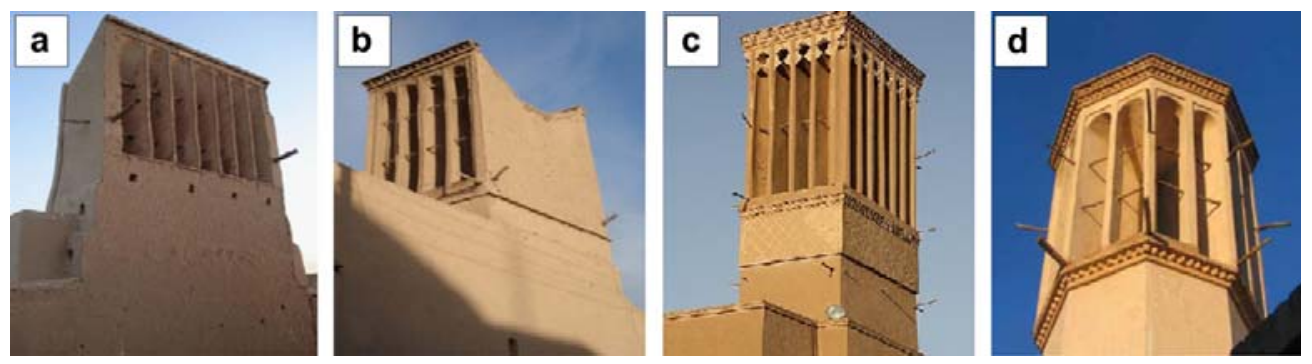

Figure 1. Traditional wind towers with different number of openings (a) one-sided, (b) twosided, (c) four-sided, (d) octahedral [Hughes et al. (2012)]

The experimental studies of windcatcher systems for all different cases are obviously costly or even impossible. Employing computational fluid dynamics (CFD) for the assessment of windcatcher 
systems' performance is a new, useful and reliable tool with reasonable accuracy [Karakastanis et al. (1986) ; Elmualim (2006)].

LES and RANS are two applicable and popular CFD techniques for simulations. In this paper, a two-sided windcatcher is modeled by using LES CFD method which is more accurate but requiring more computational efforts and the results will be analysed and compared with the achieved results from previous studies has been done by the same authors for the same model by using RANS K- $\varepsilon$ CFD technique [Niktash and Huynh (2014a; 2014b)].

\section{Modelling and computation}

A three dimensional room with the size of $5 \times 4 \times 3 \mathrm{~m}^{3}$ has been fitted with a two-sided centred position windcatcher including two-canal bottom shape and $10 \mathrm{~cm}$ bottom length with square shape is simulated using CFD-ACE+, a CFD software package from the ESI group; it is assumed that the height of windcatcher's canal type inlet/outlet duct is $2 \mathrm{~m}$ and the inlet/outlet area is $80 \times 80 \mathrm{~cm}^{2}$. Figure 2 shows the simulated room and its fitted windcatcher.



Figure 2. 3D modelled room fitted with a two-sided windcatcher

Figure 3 shows the complete system for simulation including the model with the windcatcher surrounded by the large space. The size of surrounded space has been chosen based on minimising the effect of forced flow and providing the conditions for free wind flow very similar to the real conditions. 


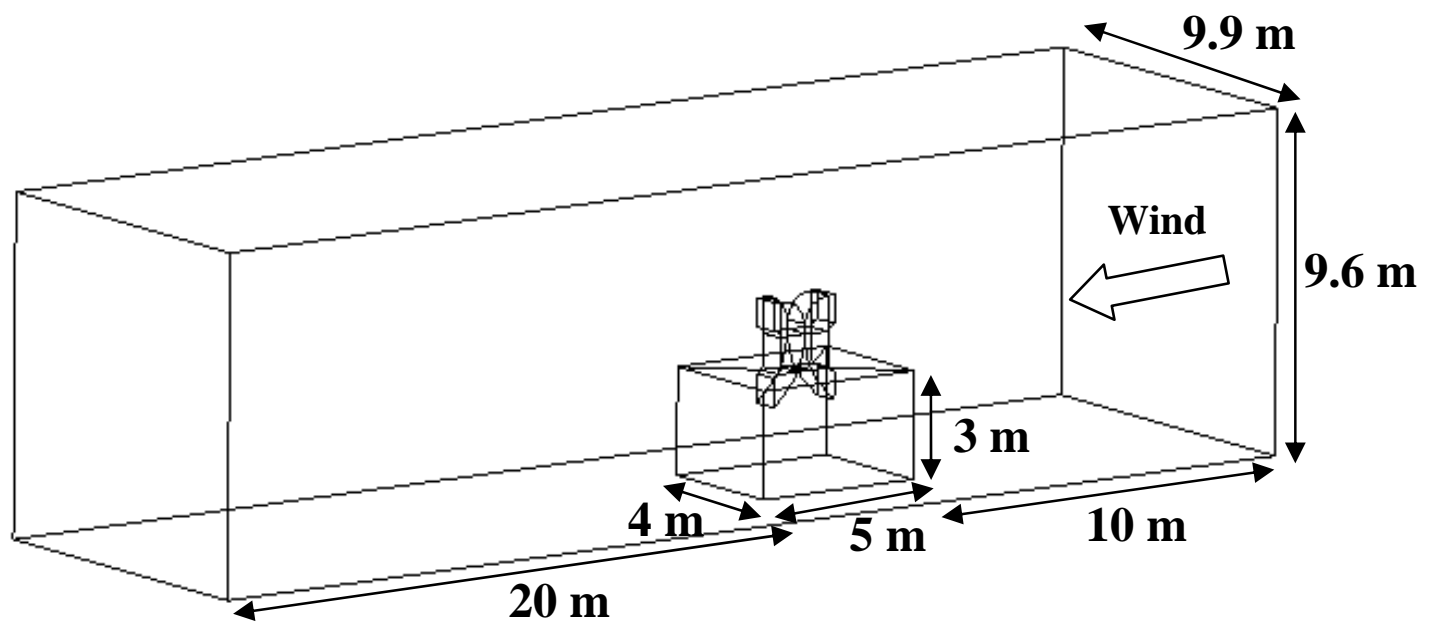

Figure 3. A complete system for simulation including the model and its large surrounded space

It is assumed that the prevailing wind direction is perpendicular to the windcatcher's inlet/outlet surface and it blows with the velocity of $3 \mathrm{~m} / \mathrm{s}$ from the right side of the surrounded space towards the modelled room and windcatcher and part of it enters the room via windcatcher's inlet and after circulation inside the room, it will exhaust through windcatcher's outlet to the outdoor and finally it will exit from left side of the surrounded space. All air properties are assumed to be constant and corresponding to air temperature as $300 \mathrm{~K}$ and air standard pressure at sea level as $101.3 \mathrm{kPa}$. To provide similar conditions with the previous studies, it has not been considered any door or window or any home accessory inside the room. Also the ventilation process is assumed to be an isothermal process to minimise the influence of thermal changes on the ventilation's quality.

To reach the sufficient accuracy in CFD simulation and due to complexity in the geometry of windcatcher's model, unstructured triangle meshes have been used throughout the whole system including room, windcatcher and the surrounded space; due to save on computational efforts and reduce accumulated errors, mesh distribution is less dense in the expected near stagnant flow regions like the room corners while dense mesh is applied for 3D model of the living area which is far from the corners of the room and windcatcher to observe the ventilation quality (Figures 4).



Figure 4. Cross section of unstructured triangle meshes in a 3D model with surrounded area 
The grid-independence study has been done for different grid numbers in the model including surrounding space to make sure that the grid pattern used is adequate.

Consequently, the total number of grids in the complete system is about 135,000 and the maximum and the minimum grid areas are about $1.4 \times 10^{-3} \mathrm{~m}^{2}$ and $1.4 \times 10^{-7} \mathrm{~m}^{2}$, respectively.

The right side of the surrounded space is defined as the inlet, the opposite side is considered as outlet. In the boundary condition part, four faces are defined as interface which let the flow pass through them; these faces are including the model's inlet/outlet and the inlet and the outlet of windcatcher's duct to the room. Figure 5 shows the defined faces of model. Some of the walls have been hidden in the figure to provide a clear view of other faces.

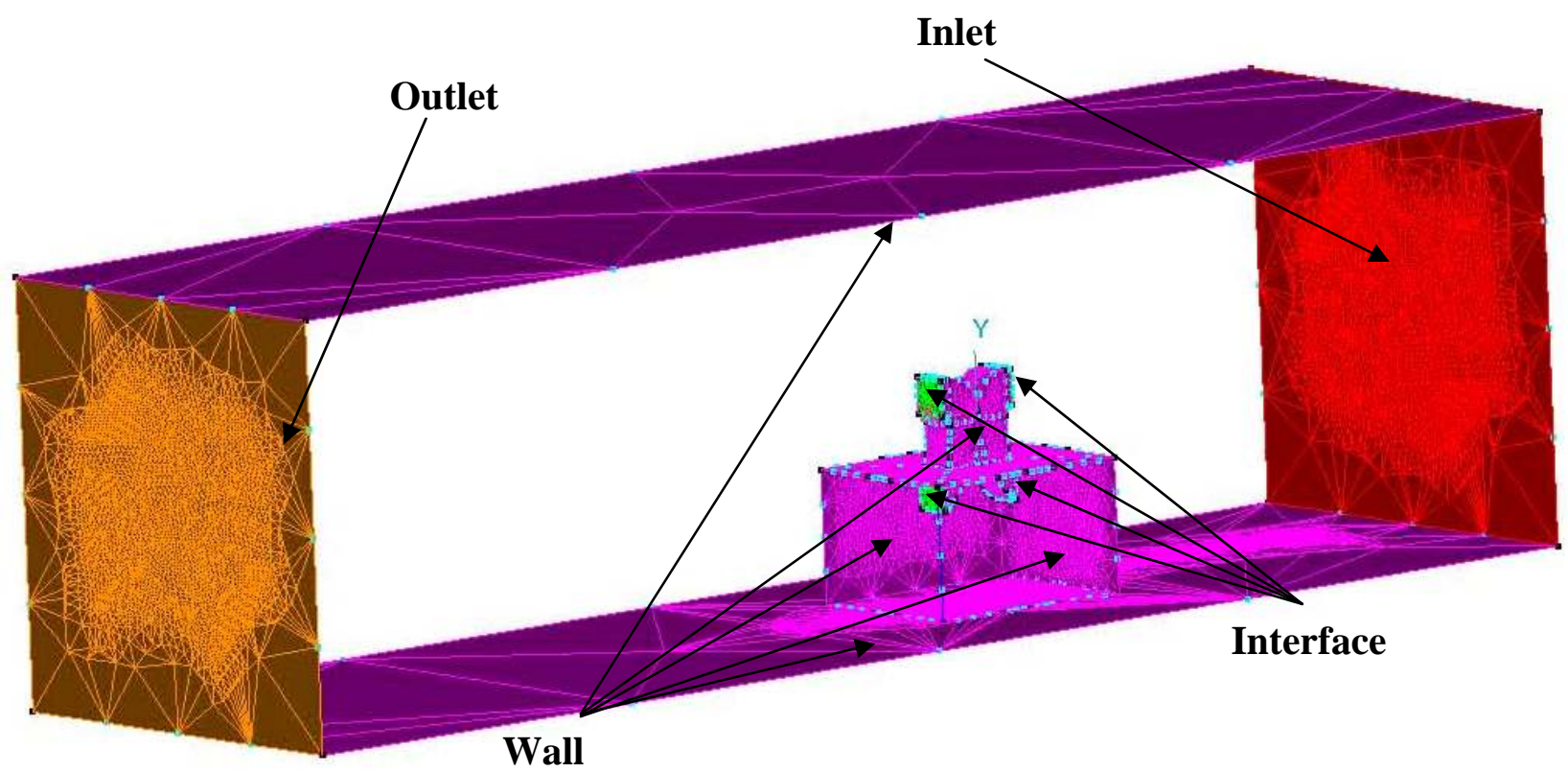

Figure 5. Defined boundary conditions for different faces of the model

Large eddy simulation (LES) is essentially a simulation that directly solves the large scale motion but approximates the small scale motion. A filtering process is used to separate out the large-scale components of the flow field from the small-scale ones. Within the finite volume method, it is rather sensible and natural to define the filter width as an average of the grid volume. The flow eddies larger than the filter width are large eddies while eddies smaller than the filter width are small eddies which require modelling. When filtering is performed on the incompressible NavierStocks equations, a set of equations very similar to the RANS equations in previous parts are obtained. Similar to RANS, there are additional terms where a modelling approximation must be introduced. In the context of LES, these terms are the subgrid scale turbulent stresses which require subgrid scale (SGS) models to close the set of equations [Tu et al. (2008)].

The most popular subgrid scale model for engineering applications is the one proposed by Smagorinsky [Smagorinsky (1963)] where in the eddy viscosity is proportional to the square of the grid spacing and the local strain rate. Since it is prescribed through the eddy viscosity assumption, it therefore shares many similarities to the formulation of the Reynolds stresses as obtained through the RANS approach [Tu et al. (2008)]. For the unsolved subgrid scale turbulent stresses, these are modeled accordingly as: 


$$
\begin{gathered}
\tau_{i j}-\frac{\delta_{i j}}{3} \tau_{k k}=-2 \vartheta_{T}^{S G S} \bar{S}_{i j} \\
\bar{S}_{i j}=\frac{\partial \bar{u}_{i}}{\partial x_{j}}+\frac{\partial \bar{u}_{j}}{\partial x_{i}}
\end{gathered}
$$

Where $\vartheta_{T}^{S G S}$ is the subgrid scale kinematic viscosity and $\bar{S}_{i j}$ is the strain rate of the large scale or resolved field.

The form of the subgrid scale eddy viscosity $\mu_{T}^{S G S}$ (noting that $\vartheta_{T}^{S G S}=\mu_{T}^{S G S} / \rho$ ) can be derived by dimensional arguments and is given by:

$$
\begin{aligned}
& \mu_{T}^{S G S}=C_{S}^{2} \rho \Delta^{2}\left|\bar{S}_{i j}\right| \\
& \left|\bar{S}_{i j}\right|=\sqrt{2 \bar{S}_{i j} \bar{S}_{i j}}
\end{aligned}
$$

Where $\Delta$ is denoted by the grid filter width and the model constant $C_{S}$ varies between 0.0065 and 0.3 depending on the particular fluid flow problem [Tu et al. (2008)]. In this work, Smagorinsky SGS model is applied and the averaged value is assumed for $C_{S}$ which is 0.15325 .

It is estimated that for the model and surrounded space totally it takes about 150 seconds to transfer flow from the inlet to the outlet of surrounded space by considering the full circulation inside the room's space. So the procedure would have 300 steps of 0.5 second which totally is 150 seconds. The convergence criteria has been defined as 0.0001 for higher accuracy.

\section{Results and discussion}

Figure 7 shows velocity magnitude at level $1.2 \mathrm{~m}$ above the floor along the room's central plane.

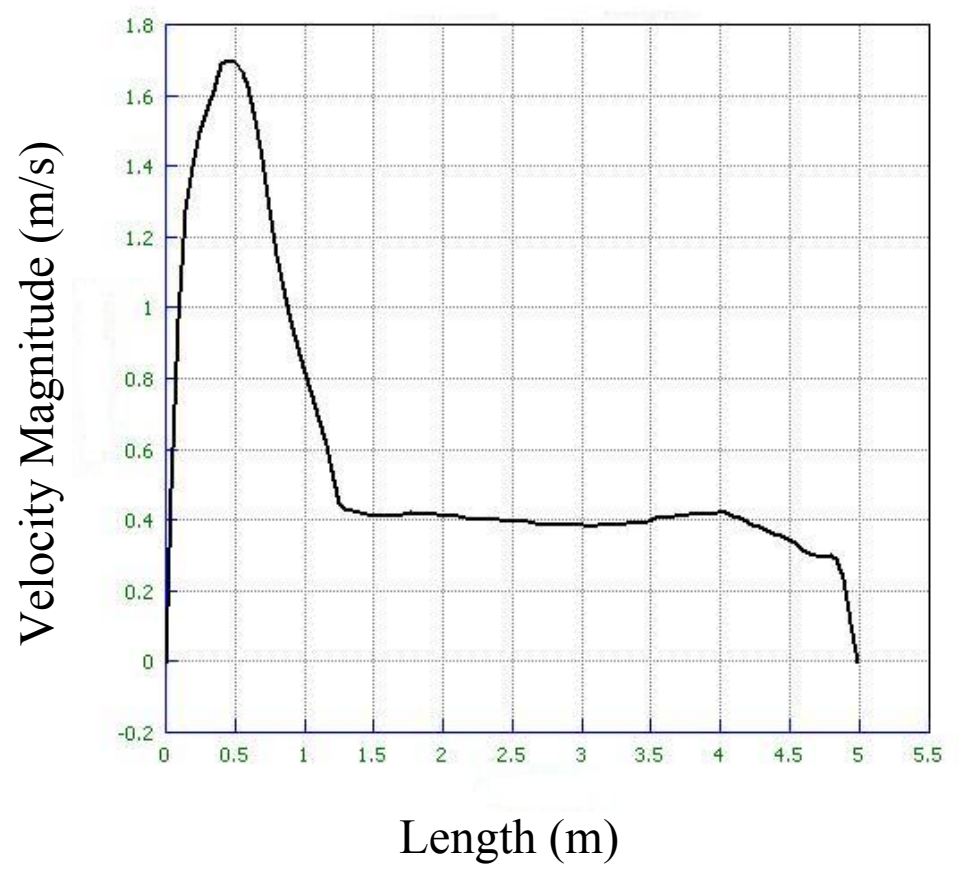

Figure 6, Velocity Magnitude at level $1.2 \mathrm{~m}$ above the floor for the model using LES method 
It is seen that the velocity magnitude at this level is approximately stable in the range of $0.36 \sim 0.41$ $\mathrm{m} / \mathrm{s}$ at the distance of $1.4 \mathrm{~m}$ to $4.4 \mathrm{~m}$ from the right wall which is about $3 \mathrm{~m}$ of the total room's length ( $60 \%$ of the total room's length).

Figure 7 compares the velocity magnitudes profiles at level $1.2 \mathrm{~m}$ above the floor in the middle of the room for the model which has been achieved via RANS K- $\varepsilon$ and LES methods.

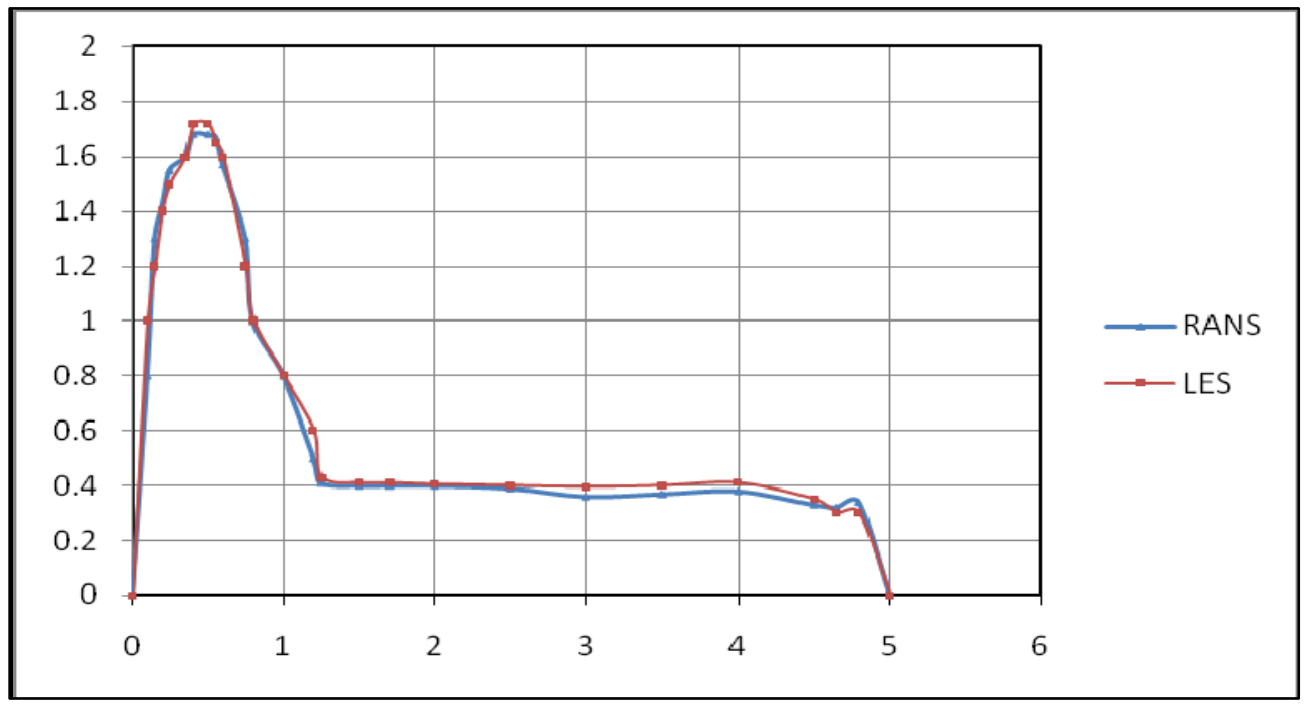

Figure 7. Comparing the calculated velocities in LES and $K-\varepsilon$ methods for the model It is seen from the profiles, there is minor difference in calculated velocity via these two CFD techniques. This small difference is due to the accuracy of LES method while the trends of velocity changes are very similar to each other. Moreover, LES method confirms the acceptable range of velocity for human comfort (less than $0.8 \mathrm{~m} / \mathrm{s}$ for indoor air speed in hot climates based on ASHRAE 2004) across the most regions of the room's length which already has been calculated and shown by using RANS method. The average difference of the two methods' results is about $5.45 \%$.

The flow traces for this model achieved by LES method is shown in Figure 8.

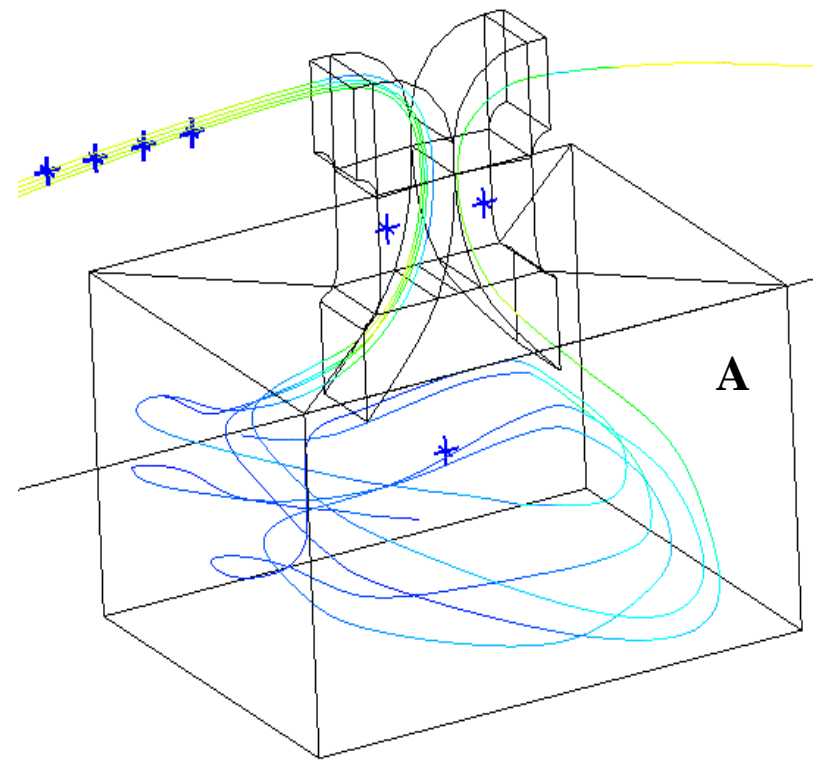

Figure 8. Some traces of flow path for the model using LES method 
As it is seen from the above flow path, there is full ventilation in the living area and the uniform flow distribution in the room while there is only a small stagnation region in top corner of the room at the right side (indicated as " $\mathrm{A}$ " in Figure 8). The average flowrate for this model is $1.075 \mathrm{~m}^{2} / \mathrm{s}$

during the defined time period.

Based on the previous studies, the flow traces for this model by using RANS K- $\varepsilon$ method is shown in Figure 9.

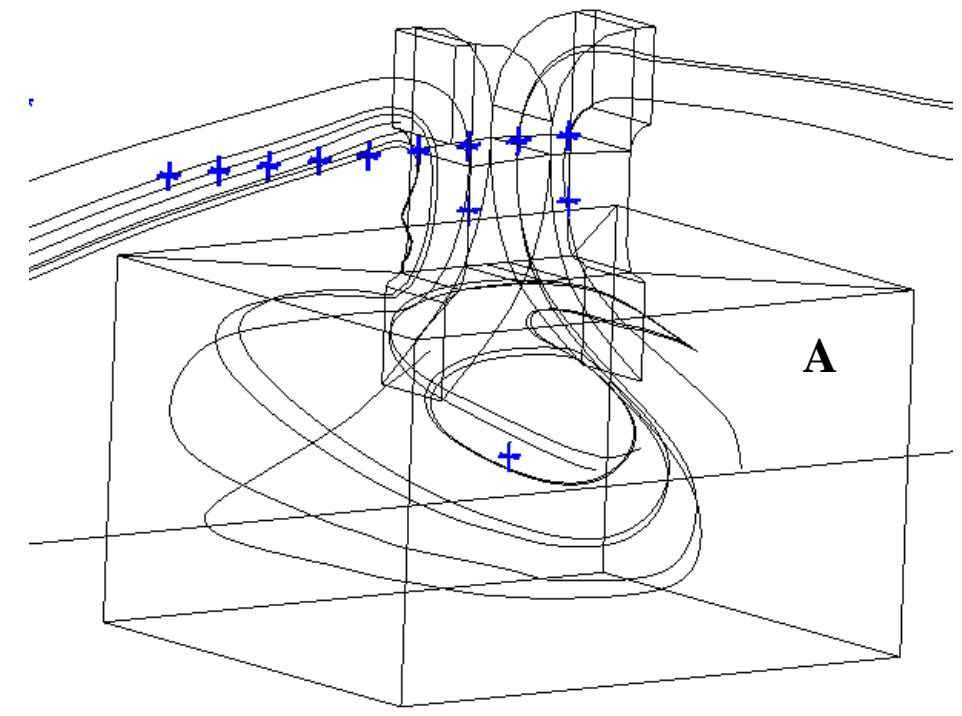

Figure 9. Some traces of flow path for the model by using RANS K- $\varepsilon$ method [Niktash and Huynh (2014b)]

As it is seen, the flowtraces are very similar to the achieved one from LES method. It verifies the RANS K- $\varepsilon$ method's results with minor difference of $4.1 \%$ (the flowrate was computed $1.119 \mathrm{~m}^{\mathrm{a}} / \mathrm{s}$ by RANS k-E method in previous studies [Niktash and Huynh (2014a;2014b)]).

\section{Conclusions}

The achieved results by LES method are so close to the RANS method results for this model and it confirms that two-sided centred position windcatcher with two-canal bottom shape, $10 \mathrm{~cm}$ bottom length with square shape, canal type inlet/outlet, $2 \mathrm{~m}$ inlet/outlet ducts height, and perpendicular inlet/outlet's surface and the wind direction provides full circulation for most part of the room and large region of stable velocity magnitude in the acceptable range of indoor air velocity for human comfort.

RANS K-E method is a useful computational method and good alternative for more accurate but time consuming LES method where very high accuracy is not required . 


\section{References}

Elmualim, A.A. (2006) Dynamic modelling of a windcatcher/tower turret for natural ventilation, Building Service Engineering Research Technology, 27, 165-182.

Fathy, H. (1986) Natural energy and vernacular architecture: principles and examples with reference to hot arid climates, The university of Chicago press, USA.

Hughes, B.R., Calautit, J.K. and Ghani, S.A. (2012), The development of commercial wind towers for natural ventilation: A review, Applied energy, 92, 606-627.

Karakatsanis, C., Bahadori, M.N. and Vickery, B.J. (1986) Evaluation of pressure coefficients and estimation of air flow rate in buildings employing wind tower, Solar Energy 37, 363-374.

Liu, L. and Mak, C.M. (2007) The assessment of the performance of a windcatcher system using computational fluid dynamics, Building and Environment 42, 1135-1141.

Montazeri, H., Montazeri, F., Azizian, R. and Mostafavi, S. (2010) Two-sided windcatcher performance evaluation using experimental, numerical and analytical modeling, Renewable Energy 35, 1424-1435.

Niktash A.R., Huynh B.P. (2014a) Numerical Simulation and Analysis of the Two-sided Windcatcher Inlet/Outlet Effect in Ventilation Flow Through a Three Dimensional Room, ASME 2014 Power Conference, USA.

Niktash A.R., Huynh B.P. (2014b), CFD Simulation and Analysis of a Two-sided Windcatcher's Inlet|Outlet Geometric Shape Effect in Ventilation Flow Through a Three Dimensional Room, 19th Australasian Fluid Mechanics Conference, Australia.

Smagorinsky, J. (1963) General circulation experiments with the primitive equations: I. The basic experiment, Monthly weather review 91, 99-164.

Tu, J., Yeoh, G.H. and Liu, C. (2008) Computational Fluid Dynamics - A Practical Approach, ButterworthHeinemann, MA, USA. 